NBER WORKING PAPER SERIES

\title{
SELF-PROTECTION INVESTMENT EXACERBATES AIR POLLUTION EXPOSURE INEQUALITY IN URBAN CHINA
}

\author{
Siqi Zheng \\ Cong Sun \\ Matthew E. Kahn \\ Working Paper 21301 \\ http://www.nber.org/papers/w21301 \\ NATIONAL BUREAU OF ECONOMIC RESEARCH \\ 1050 Massachusetts Avenue \\ Cambridge, MA 02138 \\ June 2015
}

The authors thank Professor Yinping Zhang and Professor Jinhan Mo in Department of Building Science in Tsinghua University, Professor Xiaoli Duan in Chinese Research Academy of Environmental Sciences (CRAES) for their kind research supports. The authors thank Haishi Li for excellent research assistance. The authors also thank the National Science Foundation of China (No. 71273154 and No. 71322307), Social Science Foundation of China (No. 14AJY012), Program for New Century Excellent Talents in University (NCET-12-0313), Tsinghua University Initiative Scientific Research Program for research support, and University of California at Los Angeles Ziman Center for Real Estate for generous funding. The views expressed herein are those of the authors and do not necessarily reflect the views of the National Bureau of Economic Research.

NBER working papers are circulated for discussion and comment purposes. They have not been peer-reviewed or been subject to the review by the NBER Board of Directors that accompanies official NBER publications.

(C) 2015 by Siqi Zheng, Cong Sun, and Matthew E. Kahn. All rights reserved. Short sections of text, not to exceed two paragraphs, may be quoted without explicit permission provided that full credit, including $\odot$ notice, is given to the source. 
Self-Protection Investment Exacerbates Air Pollution Exposure Inequality in Urban China Siqi Zheng, Cong Sun, and Matthew E. Kahn

NBER Working Paper No. 21301

June 2015, Revised April 2016

JEL No. Q53,Q55,R21

\begin{abstract}
$\underline{\text { ABSTRACT }}$
Urban China's high levels of ambient air pollution both lowers quality of life and raises mortality risk. China's wealthy have the purchasing power to purchase private products such as portable room air filters that allows them to offset some of the pollution exposure risk. Using a unique data set of Internet purchases, we document that households invest more in masks and air filter products when ambient pollution levels exceed key alert thresholds. Richer people are more likely to invest in air filters, which are much more expensive than masks. Our findings have implications for trends in inequality in human capital accumulation and in quality of life inequality in urban China.

Siqi Zheng

Hang Lung Center for Real Estate

Tsinghua University

Beijing, 100084, CHINA

zhengsiqi@tsinghua.edu.cn

Cong Sun

Institute of Real Estate Studies

Department of Construction Management

Tsinghua University Beijing 100084, P. R. China

suncong05@gmail.com

Matthew E. Kahn

Department of Economics

University of Southern California

KAP

Los Angeles, CA 90089

and NBER

kahnme@usc.edu
\end{abstract}




\section{Introduction}

Income inequality has been rising sharply in China. The Gini coefficient peaked at 0.491 in 2008, which was much higher than the recognized level of 0.4 (National Bureau of Statistics of China, thereafter NBSC). ${ }^{1}$ Xie and Zhou (2014) estimate that China's Gini even reached 0.50 in the year 2010. At a time when there is great interest in the causes of income inequality (Piketty 2014), it is important to examine the quality of life consequences of this trend. We study how private markets help richer people to protect themselves from China's high levels of urban air pollution. We document that richer people invest more in self protection than poorer people, and this exacerbates air pollution exposure inequality in Chinese cities.

China's urban air pollution challenges have been well documented (Zheng and Kahn 2013). At the beginning of the economic reform in the 1980s, Chinese cities suffered from black smoke produced by heavy industry, high levels of coal burning by power plants and winter heating units. This activity created extremely high levels of acid rain pollution in southern cities (He et al. 2002). In recent years, the major air pollutant has been $\mathrm{PM}_{10}$ and $\mathrm{PM}_{2.5}$ (particles with an aerodynamic diameter $<10 \mu \mathrm{m}$ or $2.5 \mu \mathrm{m}$ ) which is largely produced as a byproduct of manufacturing production, car driving and coal burning. The Asian Development Bank reports that fewer than $1 \%$ of the 500 cities in China meet the air quality standards recommended by the World Health Organization, and seven of these cities are ranked among the top ten polluted cities in the world (Asian Development Bank, 2012).

Pollution exposure impacts both the quantity and quality of life (MacKerron and Mourato 2009; Hall et al. 2010). Breathing polluted air as measured by particular matter (PM) raises one's risk of heart and lung disease (Chay and Greenstone 2003; Evans and Smith 2005; Moretti and Neidell 2011; Pope et al. 2011). Chen et al. (2013) use the Huai River winter heating policy as a natural experiment to examine the impact of air pollution on life expectancy reduction in China, and find that the higher PM concentrations in the north caused by winter heating lower 5.5 years of life expectancy. ${ }^{2}$ Ebenstein et al. (2015) document that life expectancy in China has increased by less than what would be predicted given its per-capita income growth. They argue that rising air pollution levels is a key explanation for this life expectancy gap.

\footnotetext{
1 According to United Nation's standard, Gini index above 0.4 signals a large income inequality.

2 In China, cities north to the Huai River and Qinling Mountain receive subsidized coal-based heating in winter months, while cities south to this Huai River line are not entitled to this subsidized heating.
} 
Pollution exposure also has direct impacts on human capital accumulation and utilization. James Heckman's research posits a dynamic complementarity effect such that young children learn more in school if they are healthier (Heckman 2007). According to his model, children with worse health learn less in school and this compounds over time so that these children are less likely to achieve their full potential. Pollution exposure increases school absences and lowers test performance (see Currie et al. 2009; Zweig et al. 2009; Currie et al. 2014). Human capital attainment is negatively affected by life time pollution exposure (Graff Zivin and Neidell 2013). Given China's one child policy, parents have strong incentives to invest in a variety of strategies to protect their only child's health in the face of very high levels of local pollution.

There are two strategies for reducing the damage caused by air pollution. First, the government can introduce regulations to reduce emissions from various polluting sectors such as power generation, industry, transportation, and construction. Second, private individuals can invest in variety of environmental defensive strategies for reducing their exposure to current levels of outdoor pollution. While investments in public goods (the first strategy) broadly benefit everyone, investments in private self protection mainly benefit the individuals who choose this option (Antoci 2009). Individuals gain private benefits from investing in self-protection and averting behavior (Smith et al. 1995; Graff Zivin and Neidell 2009; Janke 2014).

We use data from China to study private household investments to reduce their exposure to outdoor air pollution. To study private protective actions, we use a unique panel data base of online sales indices assembled by Taobao.com (see Section 3 for details). From Taobao.com, we obtained daily sales indices by city for all buyers, and also monthly sales indices by city for sub-groups of buyers (such as high-income, middle-income and low-income buyers). We use the city level data to study how household private investment in self protection varies as a function of government announcements concerning the severity of the level of air pollution and to study how these consumption dynamics differ between rich, middle class, and poorer Chinese urbanites. We find that all groups respond to government announcements of severe pollution by investing more in self protection but that only the richest group increase their purchases of the most effective, and most expensive anti-pollution devices (portable room air filters) when local pollution levels are higher.

The rest of the paper is organized as follows: Section 2 reviews the empirical and 
theoretical studies on self-protection strategies and pollution exposure inequality. Section 3 describes data, two hypotheses and the corresponding models. Section 4 presents the empirical results testing our two hypotheses, followed by conclusions and discussions in Section 5.

\section{Self-Protection Strategies and Pollution Exposure Inequality}

\subsection{A taxonomy of available self-protection strategies in Chinese cities}

By choosing a city and a neighborhood within that city, urban residents have some control over their exposure to air pollution. Cross-county migration research documents that households reveal a high willingness to pay for clean air in the US (Bayer et al. 2009; Chay and Greenstone 2005). Using data from within the Los Angeles metro region, Sieg et al. (2004) document that when the Clean Air Act's successful implementation reduced smog levels in specific communities that this attracted richer people to move to such communities.

China's central government has been reforming the hukou registration system in the past three decades, and the restriction on labor mobility has been largely relaxed. People are free to choose which city and which location within a city to live. Job opportunity and quality of life are two major attractions a city can provide. Local public services (such as schools, healthcare facilities) and environmental quality are key determinants of local quality of life. Zheng et al. (2014) study standardized home prices across China's major cities and find that, all else equal, a 10\% decrease in imported neighbor pollution is associated with a $0.76 \%$ increase in local home prices. They also report that the marginal valuation for clean air is larger in richer Chinese cities. Within Beijing, people have a higher willingness to pay for those locations with better air quality, such as the northwest part in Beijing. Using cross-sectional data on real estate prices across Beijing, Zheng and Kahn (2008) find that, all else equal, a home's price is $4.1 \%$ higher at the location with a $10 \mu \mathrm{g} / \mathrm{m}^{3}$ lower average $\mathrm{PM}_{10}$ concentration.

One's residential location alone is not sufficient for describing one's pollution exposure. When the outdoor air is polluted, people will prefer to drive private cars (rather than walking on the street), and they will also decrease their time spent outdoors (Neidell 2009). Based on the estimate in Chen and Zhao (2011), the indoor PM concentration is on average about $80 \%$ of the outdoor concentration in Chinese cities, so people can breathe less polluted air when they are indoors on polluted days. 
Moreover, modern buildings in Chinese cities have HVAC air conditioning systems with air filtering which further improves the indoor air quality.

China's nascent market economy offers households a growing array of products intended to improve day to day quality of life. In the case of avoiding air pollution, masks and air pollution filters represent key examples of such market products. During a hazy week at the end of 2013, mask and portable room air filter sales reached 760,000 and 140,000 respectively, with the weekly growth rates (compared to the previous week) of $52.35 \%$ and $74.1 \%$ respectively. Air filters are more effective (but also more expensive) than masks in protecting people against air pollution. Research conducted by the Department of Building Science at Tsinghua University, and tests conducted by China Consumer Association show that the mean effectiveness of masks and air filters is $33.0 \%$ and $92.0 \%$ respectively. That is, people with masks or air filters are exposed to $67.0 \%$ or $8.0 \%$ of the original $\mathrm{PM}_{2.5}$ concentration, respectively. ${ }^{3}$

\subsection{Pollution Exposure Inequality Resulted from self-protection strategies}

Differential investments in these items between the rich and poor will exacerbate pollution exposure differences and hence increase health inequality. As shown in the cross-city and within-city compensation differentials studies in Chinese cities discussed above (Zheng et al. 2014; Zheng and Kahn 2008), real estate prices are higher and housing demand is higher in less polluted geographic areas. Thus, the poor live in dirtier areas within a city.

Richer people have a higher probability of owning cars, which protect them from the outdoor dirty air. Using micro-data from the 2006 Chinese Urban Household Survey conducted by NBSC, Zheng et al. (2011) estimate the income elasticity of car ownership is 0.81 . Poorer people are more likely to commute to work by public transit or by motorbike and this requires them to stay outside for longer time. Low-skilled workers are also more likely to work in outdoor occupations such as construction, street cleaning and package delivery. In contrast, high-skilled workers work indoors. According to the Environmental Exposure Related Activity Patterns Survey in China, the ratio of office staffs' average daily outdoor time to that for all workers is 0.64. Furthermore, richer people are more likely to have air conditioning, which means windows can be closed on hot days with high pollution levels.

For air filters and masks, the former is much more expensive than the latter. An

\footnotetext{
${ }^{3}$ See: http://www.cca. org.cn/web/xfzd/newsShow.jsp?id=67720.
} 
average portable room air filter costs 490 US dollars, while an average mask only costs and 0.9 US dollars. Consumers have to change the air filter's strainer once per year but a mask only last for about ten days. Thus, the daily user cost (including electricity expenditure) of an air filter is more than ten times that of a mask. The sales data of masks and air filters on Taobao.com in 2013 shows, the high-income group (the top $25 \%$ of total consumers) bought $31.9 \%$ of masks and $47.9 \%$ of air filters.

Recent research has studied the consequences of inequality for mitigating pollution exposure. Hotte and Winer (2012) model the optimal investment in private mitigation efforts to reduce pollution exposure. Their model yields the prediction that pollution mitigation efforts increase with the pollution level and with income. This means that poor people spend less to protect themselves. They present a general equilibrium model featuring both the production of pollution and the population's optimal response to exposure to this pollution. Antoci et al. (2012) also explicitly write out a general equilibrium model of pollution production and exposure. Bernard et al. (2014) model private self protection and environmental regulation as substitutes. In this case, effective regulation is likely to crowd out individual self protection.

Each of these theoretical studies is relevant for our work. In our study, we adopt a partial equilibrium approach. The Chinese urbanites are exposed to a high level of air pollution. Holding government regulation constant, people choose how to self protect themselves. Given the extremely high levels of air pollution in Chinese cities, we do not believe that increased regulatory efforts to reduce urban air pollution will crowd out private self protection.

A novel feature of our study is explicitly introducing a spatial context where cities differ with respect to their pollution exposure and income. In this sense we exploit within nation variation, to test the self protection hypothesis.

\section{Data and Models}

\subsection{Data}

Many urban residents in major cities purchase products online. This fact allows us to build a novel data base. Alibaba Group is China's largest e-commerce company and it provides the largest online shopping platform Taobao.com (with hundreds of million online consumers) in China similar to eBay and Amazon. Taobao.com accounts for about $90 \%$ of the online Consumer-to-Consumer sales and $57 \%$ of online Business-to- 
Consumer sales in China ${ }^{4}$. iResearch reports that Taobao's gross sales volume exceeded 1 trillion RMB Yuan in the first eleven months in 2012, which accounted for about $5.4 \%$ of China's sales of retail consumer goods in that year. ${ }^{5}$ Many daily consumption items are purchased on Taobao.com because of its low prices and easy shipping. Our core data set for city level sales of self-protection products is based on data from Taobao.com. According to Taobao's statistics, Chinese consumers spent 870 million yuan (US\$143 million) on 4.5 million online transactions purchasing anti-smog products in 2013. While concerns about the "digital divide" raise the possibility that the poor are less likely to shop online, low income people in China prefer to use Taobao because its prices are lower than bricks and mortar stores. It is likely that some of the very poor people and the elderly may not use Taobao because they do not know how to use a computer or have access to the Internet.

Taobao.com provides daily and monthly sales indices of each market good covering the 34 major cities (all municipalities directly under the central government, provincial capital cities, and quasi provincial capital cities, excluding Lhasa in Tibet). By consulting the designers of this sales index at Taobao.com, we learned that the equation used to construct the sales index from the real sales volume is a linear function and the key parameters are constant for all income groups, all cities/regions and over the whole study period (We do not know the exact values of the parameters). ${ }^{6}$ Therefore, we choose to directly use the sales indices in our regressions, and this will not affect the estimates of our key coefficients.

We collect the daily sales index data from November 1, 2013 to January 31, 2014. This three-month time period covers a large number of foggy and hazy days, including the severe haze at the end of 2013. In December 2013, the Pearl River Delta, where Shanghai and Nanjing are located, suffered from the most severe haze event of the past ten years. Beijing and Shijiazhuang also experienced terrible days of haze in December 2013 and January 2014. We also collect monthly sales indices from April 2013 to April 2014 for each of the three income groups (high-income, middle-income and lowincome). These categories correspond to consumers within the $75 \%-100 \%$ percentile ("high-income"), 25\%-75\% percentile ("middle-income") and 0\%-25\% percentile

\footnotetext{
4 http://dealbook.nytimes.com/ 2013/09/25/alibaba-said-to-shift-target-from-hong-kong-to-u-s-for-i-p-o/

5 http://www.iresearchchina.com/views/4730.html

6 The algebra equation is: real sales volume $j t=\theta_{0}+\theta_{1} \times$ Sales index $j$. Both $\theta_{0}$ and $\theta_{1}$ are constant for all income groups, all cities/regions and over the whole study period. The exact values of these two parameters are not released by Taobao.com due to confidential consideration. Mu and Zhang (2014) estimate that $\theta_{1}$ is about 63 on average. Given that the two parameters are constant, we choose to directly use the sales index in our regressions, and this will not affect the estimates of our key coefficients.
} 
("low-income") in the distribution of the overall distribution of consumers' purchase expenditures. Unfortunately we are unable to access daily index data by income group.

The air pollution data and the daily pollution alerts are obtained from China's Ministry of Environmental Protection (MEP). Daily and monthly $\mathrm{PM}_{2.5}$ concentrations are calculated from the MEP's official hourly real-time data. According to China's new Ambient Air Quality Standards (GB3095-2012) released by MEP, there are six levels of pollution alerts: excellent, good, lightly polluted, moderately polluted, heavily polluted and severely polluted. The thresholds of those alert are based on the air quality index constructed by the MEP. Fu et al. (2014) list the detailed thresholds of the air quality index for each alert. MEP releases hourly air pollution alert of these cities on its website, ${ }^{7}$ and each city's Bureau of Environmental Protection releases its city's alert on its own website. People can also access this information through several mobile phone apps. We obtained city level historical weather record such as daily temperature, humidity, wind speed and presences of rain, snow and fog from the website TuTiempo.net. ${ }^{8}$

The recent public campaign in China has urged the state to create a nationwide $\mathrm{PM}_{2.5}$ monitoring network. The recent MEP official $\mathrm{PM}_{2.5}$ data and the US embassy $\mathrm{PM}_{2.5}$ data provide consistent readings. For instance, the mean value of the US Embassy $\mathrm{PM}_{2.5}$ reading in 2013 is $87.4 \mu \mathrm{g} / \mathrm{m}^{3}$, and that for the MEP official $\mathrm{PM}_{2.5}$ reading at the air quality monitor near the US Embassy in Beijing is $90 \mu \mathrm{g} / \mathrm{m}^{3}$. Therefore Chinese urbanites have been gaining confidence in the MEP's air pollution alerts. In the case of the United States, information disclosure regulation has been documented to have success in increasing household self protection investment (Neidell 2004, 2009), and this may also happen in China.

Variable definitions and summary statistics are listed in Table 1. Summary statistics of the control variables, such as weather attributes and national holidays, are not listed but are available upon request.

*** Insert Table 1 about here $* * *$

\subsection{Hypotheses and Models}

\footnotetext{
7 http://113.108.142.147:20035/emcpublish/

8 http://www.tutiempo.net/en/Climate/China/CN.html
} 
The online purchase data allow us to test the following two hypotheses.

Hypothesis \#1: People respond to higher levels of air pollution by buying more masks and filters. They respond to both government's pollution alerts (determined by $\mathrm{PM}_{2.5}$ exceeding key thresholds) and to the level of outdoor $\mathrm{PM}_{2.5}$. Market Internet purchases of other goods (socks and towels) are not correlated with pollution alerts and the level of outdoor $\mathrm{PM}_{2.5}$.

Hypothesis \#2: Compared to poorer people, richer people invest more in selfprotection products when air pollution is higher.

To test Hypothesis \#1, we estimate a model as presented in equation (1):

$$
Q_{i t}=\alpha_{0}+\alpha_{1} \cdot \ln \left(P M_{i t}\right)+\alpha_{2} \cdot A_{i t}+\alpha_{3} \cdot X_{i t}+\alpha_{4} \cdot T_{t}+\alpha_{5} \cdot C_{i}+\varepsilon_{i t}
$$

The unit of analysis for Equation (1) is city/day. $Q_{i t}$ is the sales index of each market product (masks or air filters) in city $i$ in day $t$. Here we use the daily sales index data which is available for the short three-month period (from November 1, 2013 to January 31,2014$). P M_{i t}$ is the daily $\mathrm{PM}_{2.5}$ concentration in city $i$ in day $t$. Four pollution alert dummies are included as $A_{i t}$. ("blue sky" days, with the alert being either "excellent" or "good", as the default). $X_{i t}$ is a vector of weather attributes and control variables such as China's national holidays. Weather attributes include daily mean temperature, humidity, wind speed and several dummies like rainfall, snow and fog. The two variable $T_{t}$ and $C_{i}$ represent time trend and city-fixed effects, to control for the time trend in sales and unobserved city attributes, respectively. $\varepsilon_{i t}$ is a disturbance term. We cluster the standard errors by city.

The sales index is the count data, so we estimate Equation (1) using a count model. We will use both negative binomial and Poisson models. In addition, this sales index contains some zero-value observations, because a city may have zero sales of air filters or masks on Taobao.com in a single day. To address this issue, we employ the zeroinflated versions of both count models (Lambert 1992; Cameron and Englin 1997; Sheu et al. 2004; Silva and Tenreyro 2006; Helpman et al. 2008). The Vuong test is performed to see if zero-inflated models are more appropriate (Vuong 1989; Greene 1994).

We estimate equation (2) to test Hypothesis \#2:

$$
\begin{aligned}
Q_{i j t}=\beta_{0} & +\beta_{1} \cdot \ln \left(P M_{i t}\right)+\beta_{2} \cdot \ln \left(P M_{i t}\right) \cdot \text { middle income }_{i}+\beta_{3} \cdot \ln \left(P M_{i t}\right) \cdot \text { high income }_{i}+ \\
& +\beta_{4} \cdot \text { middle income }_{i j}+\beta_{5} \cdot \text { high income }_{i j}+\beta_{6} \cdot W_{i t}+\beta_{7} \cdot T_{t}+\beta_{8} \cdot C_{i}+v_{i j t}
\end{aligned}
$$


In equation (2), the unit of analysis is city/month/income group. Each city has three sales index series for low-income, middle-income and high-income buyers. Such income group specific sales indices are only available for monthly basis but for a longer time period (from April 2013 to April 2014). $Q_{i j t}$ is income group $j$ (1=low-income, $2=$ middle-income, $3=$ high-income)'s sales index of each market product in city $i$ in month $t$. middle income $_{i}$ and high income $_{i}$ are two income group dummies for city $i$ (low-income group is the default category). $W_{i t}$ is a vector of monthly weather attributes, such as mean temperature, humidity, wind, and frequency of rainy day, snowy day and foggy day. The coefficient $\beta_{2}$ (or $\beta_{3}$ ) of the pollution-income interaction term measures the differential of the response gradient to pollution increases between the middle income group (or high-income group) and the low income. The coefficient $\beta_{4}$ (or $\beta_{5}$ ) measures the "absolute" sales index gap between the middle-income group (or highincome group) and the low-income group. $v_{i j t}$ is a disturbance term. We will first report count model results, and then change the dependent variable to $\ln ($ sales index +1$)$ and run an OLS regression (we add 1 to the sales index to avoid the elimination of zerovalue observations). We report OLS regressions here because of the ease of interpreting the coefficients $\left(\beta_{2}\right.$ or $\left.\beta_{3}\right)$ as the elasticities (\% change in mask/filter sales with $1 \%$ increase in $\mathrm{PM}_{2.5}$ concentration, for each of the three income groups).

As placebo tests, we also report regression results based on equations (1) and (2) where we replace the sales indices for air filters and masks with those for sales of socks and towels. We expect that there will be no causal relationship between the outdoor level of air pollution and the purchase of these products.

\section{Empirical Results}

\subsection{Results testing Hypothesis \#1}

We seek to study how the sales of masks and filters evolves as a function of a city's local daily $\mathrm{PM}_{2.5}$ concentration level and the local government's alerts about the severity of air pollution on that day in Table 2 (Hypothesis 1).

\footnotetext{
*** Insert Table 2 about here ***
}

In Table 2, the dependent variable in odd columns is the daily sales of masks, and 
that in even columns is the daily sales of air filters. The omitted category of government alert is a "blue sky" day. Columns (1) and (2) report the regression results using standard negative binomial model as the benchmark. We report zero-inflated negative binomial model results in columns (3) and (4), and then zero-inflated Poisson model results in columns (5) and $(6)^{9}$. The key results are stable over different model choices. Vuong statistics show that zero-inflated versions are more appropriate given the data structure.

The results show that, Chinese households respond to government's pollution alerts and also respond to the PM level. Note the monotonic relationship between the severity of the government alerts and the sales of masks and filters. Also note the significant increases of mask and air filter sales when the pollution alert becomes "severely polluted". Based on the coefficients in columns (5) and (6), the daily sales of masks on the days when the government has issued a "heavily polluted" and "severely polluted" alert are 2.9 and 7.2 times those during a "blue sky" day. These two ratios are 1.6 and 3.0, respectively for air filter sales. This evidence suggests that the urbanites trust the government's pollution alerts.

Controlling for the discrete government alert, consumers also respond to the actual $\mathrm{PM}_{2.5}$ concentration level by buying self-protection products, as indicated by the significant coefficients of $\ln \left(\mathrm{PM}_{2.5}\right)$. People can check their smartphones for real time updates about the reading of current $\mathrm{PM}_{2.5}$ concentration, and they do so more frequently on the days when the government announces a "heavily polluted" or a "severely polluted" alert. This effect is larger for masks but weaker for air filters. This may be attributed to the cost differential between these two products - an air filter is much expensive than a mask.

Based on a similar Taobao.com transaction data set, in an independent work, $\mathrm{Mu}$ and Zhang (2014) find that a 100-point increase in Air Quality Index increases the consumption of all masks by 54.5 percent and anti-PM 2.5 masks by 70.6 percent. These results are consistent with our findings here but our emphasis is on cross income group exposure differences and hence on the role of income inequality, as we discuss in the subsection below.

\subsection{Results Testing Hypothesis \#2}

To test whether richer people invest more in self protection, we use the monthly Internet sales data stratified by the three income categories and test whether richer

\footnotetext{
9 We also employ pseudo maximum likelihood Poisson model to estimate equation (1), and the coefficients are similar with those in the last two columns of Table 2, which are available upon request.
} 
people are purchasing more masks and filters on more polluted days. The government alert variables are not available for this longer period, so the key independent variable is the monthly mean $\mathrm{PM}_{2.5}$ concentration, and we interact this variable with income group dummies. We first estimate equation (2) using zero-inflated Poisson model (columns (1) and (2) in Table 3). We then switch to OLS regressions with $\ln \left(Q_{i j t}+1\right)$ as the dependent variable, in order to obtain the elasticity estimates (columns (3) and (4)). We also test if the results are stable if we do not add 1 to the sales index in the OLS regressions (columns (5) and (6)).

*** Insert Table 3 about here ***

The coefficients of $\ln (\mathrm{PM} 2.5)$ is statistically significant for the mask regressions (odd columns) but loses its significance in the air filter regressions (even columns). This indicates that, when the air becomes more polluted, that the low-income group buy more masks, but not air filters. This finding may be due to the fact that masks are cheap so that even the poor can afford them. Many of the poor work outside and thus have a greater incentive to invest in cheap masks.

In Table 3, we report results in which we interact the consumer's income category with the ambient air pollution level. Based on the results in column (1), we find that the high-income group buys more masks than the low-income group as the $\mathrm{PM}_{2.5}$ concentration increases. The mask sales indices for the high-income and the lowincome groups rise by 1.3 and 0.4 in absolute value when the $\mathrm{PM}_{2.5}$ concentration rises by $1 \%$ from its average value. This represents a $0.6 \%$ and $0.5 \%$ increase from their original sales indices, respectively. As shown in columns (3) and (5), we report pollution elasticites and the rich do not exhibit a significantly higher mask/pollution elasticity than the poor.

In contrast, the air filter is quite expensive and its main function is cleaning the indoor air. As expected, the income gradient for air filter purchases is statistically significant, in both the zero-inflated Poisson and OLS models. The low-income group has a nearly zero elasticity of air filter purchases with respect to $\mathrm{PM}_{2.5}$ increases, while both the middle-income and high-income groups have a positive and statistically significant elasticity of roughly 0.2 . Those elasticity estimates clearly show that rich people respond more when the air gets dirtier by buying more air filters which are 
expensive but effective in cleaning the indoor air.

\subsection{Placebo tests}

Table 4 reports placebo test results. In those regressions, we change the dependent variables to the Internet sales of socks and towels. These products do not offer self protection against outdoor air pollution. The model specifications in the first two columns are the same with columns (5) and (6) in Table 2, and those in the last four columns are the same with columns (1) to (4) in Table 3.

In the case of socks and towels, we find no evidence of increased sales as a function of government alerts of the severity of the pollution. In fact, we find that sales of these items decline on days when the pollution is especially severe. As shown by the $\ln \left(\mathrm{PM}_{2.5}\right)$ coefficients in columns (1) and (2), we do find that within pollution threshold categories that there is no positive correlation between $\mathrm{PM}_{2.5}$ concentrations and socks and towel sales. In columns (3) to (6), the coefficients of interaction terms are almost all statistically insignificant.

\section{Conclusion}

Chinese urbanites engage in self-protection against air pollution and richer individuals are more likely to make these investments. For a given level of outdoor air pollution, an individual can reduce her exposure by spending less time outside, and wearing a mask when one is outside. Such an individual can reduce her exposure to indoor air pollution by purchasing an effective filter. Based on a unique data set of Internet purchases, we study household investment in two different self protection products varies as a function of ambient city pollution levels exceeding key alert thresholds. The sales of masks on the days when the government has issued a "heavily polluted" and "severely polluted" alert are 2.9 and 7.2 times those during a "blue sky" day. These two ratios are 1.6 and 3.0 respectively for air filter sales. Controlling for the discrete government alert, consumers also respond to the actual $\mathrm{PM}_{2.5}$ concentration level by buying more masks and air filters.

We also find that richer people invest more in self protection products, especially the more expensive but more effective devices like air filters, when air pollution is higher. The low-income group exhibits a very flat air filter purchase propensity as a function of $\mathrm{PM}_{2.5}$ concentration increases, while the middle-income and high-income groups have an elasticity of roughly 0.2 . Air filters are more effective than masks in 
protecting people from air pollution. This poor versus rich differential propensity to invest in self protection means that air pollution exposure exacerbates quality of life inequality in Chinese cities because the poor are exposed to more risk. ${ }^{10}$

Given the investment differentials we have documented, future research could use a field experiment research design in which the urban poor are randomly selected to receive information about the day to day pollution exposure they face. A more expensive field experiment would subsidize the purchase price of masks and air filters. The research could then test whether mask and air filter purchases increase for the treatment group and by how much. Such research would be useful for judging how much of the rich/poor investment gap is due to information access versus price effects.

\section{Acknowledgements}

The authors thank Professor Yinping Zhang and Professor Jinhan Mo in Department of Building Science in Tsinghua University, Professor Xiaoli Duan in Chinese Research Academy of Environmental Sciences (CRAES) for their kind research supports. The authors thank Haishi $\mathrm{Li}$ for excellent research assistance. The authors also thank the National Science Foundation of China (No. 71273154 and No. 71322307), Social Science Foundation of China (No. 14AJY012), Program for New Century Excellent Talents in University (NCET-12-0313), Tsinghua University Initiative Scientific Research Program for research support, and University of California at Los Angeles Ziman Center for Real Estate for generous funding.

\footnotetext{
${ }^{10}$ We combined our regression results with other datasets, such as the Environmental Exposure Related Activity Patterns Survey of Chinese Population and existing experiments on the effectiveness of self-protection products. A rough estimate shows that the surrounding $\mathrm{PM}_{2.5}$ concentration for poor people is about $28 \%$ higher than rich people on average.
} 


\section{References}

Antoci, A., 2009. Environmental degradation as engine of undesirable economic growth via self-protection consumption choices. Ecological Economics 68, 1385-1397.

Antoci, A., Russu, P., Ticci, E., 2012. Environmental externalities and immiserizing structural changes in an economy with heterogeneous agents. Ecological Economics 81, 80-91.

Asian Development Bank. (2012). Toward an Environmentally Sustainable Future: Country Environmental Analysis of the People's Republic of China. (Available at: http://www.adb.org/sites/default/files/pub/2012/toward-environmentally-sustainablefuture-prc.pdf)

Bayer, P., Keohane, N., Timmins, C., 2009. Migration and hedonic valuation: The case of air quality. Journal of Environmental Economics and Management 58, 1-14.

Bernard, S., Hotte, L., Winer, S.L., 2014. Democracy, inequality and the environment when citizens can mitigate health consequences of pollution privately or act collectively. European Journal of Political Economy 34, 142-156.

Cameron, T.A., Englin, J., 1997. Respondent experience and contingent valuation of environmental goods. Journal of Environmental Economics and management 33, 296-313.

Chay, K.Y., Greenstone, M., 2003. The impact of air pollution on infant mortality: evidence from geographic variation in pollution shocks induced by a recession. The Quarterly journal of economics 118, 1121-1167.

Chay, K.Y., Greenstone, M., 2005. Does air quality matter? Evidence from the housing market. Journal of Political Economy 113, 376-424.

Chen, C., Zhao, B., 2011. Review of relationship between indoor and outdoor particles: I/O ratio, infiltration factor and penetration factor. Atmospheric Environment 45, 275-288.

Chen, Y., Ebenstein, A., Greenstone, M., Li, H., 2013. Evidence on the impact of sustained exposure to air pollution on life expectancy from China's Huai River policy. Proceedings of the National Academy of Sciences 110, 12936-12941.

Currie, J., Graff Zivin, J., Mullins, J., Neidell, M., 2014. What do we know about short-and long-term effects of early-life exposure to pollution? Annual Review of Resource Economics 6, 217-247.

Currie, J., Hanushek, E.A., Kahn, E.M., Neidell, M., Rivkin, S.G., 2009. Does pollution increase school absences? The Review of Economics and Statistics 91, 682-694.

Ebenstein, A., Fan, M., Greenstone, M., He, G., Yin, P., Zhou, M., 2015. Growth, pollution, and life expectancy: China from 1991 - 2012. American Economic Review 105, $226-231$.

Evans, M.F., Smith, V.K., 2005. Do new health conditions support mortality - air pollution effects? Journal of Environmental Economics and Management 50, 496-518.

Fu, Q., Fang, Z., Villas-Boas, S.B., Judge, G., 2014. An investigation of the quality of air data in Beijing. (Available at http://are.berkeley.edu/ sberto/BeijingJuly16.pdf) 
Graff Zivin, J., Neidell, M., 2009. Days of haze: Environmental information disclosure and intertemporal avoidance behavior. Journal of Environmental Economics and Management $58,119-128$.

Graff Zivin, J., Neidell, M., 2013. Environment, Health, and Human Capital. Journal of Economic Literature 51, 689-730.

Greene, W.H., 1994. Accounting for excess zeros and sample selection in Poisson and negative binomial regression models. (Available at http://ssrn.com/abstract=1293115)

Hall, J.V., Brajer, V., Lurmann, F.W., 2010. Air pollution, health and economic benefitsLessons from 20years of analysis. Ecological Economics 69, 2590-2597.

He, K., Huo, H., Zhang, Q., 2002. Urban air pollution in China: current status, characteristics, and progress. Annual review of energy and the environment 27, 397-431.

Heckman, J.J., 2007. The economics, technology, and neuroscience of human capability formation. Proceedings of the National Academy of Sciences 104, 13250-13255.

Helpman, E., Melitz, M.J., Rubinstein, Y., 2008. Estimating trade flows: trading partners and trading volumes. Quarterly Journal of Economics 123, 441-487.

Hotte, L., Winer, S.L., 2012. Environmental regulation and trade openness in the presence of private mitigation. Journal of Development Economics 97, 46-57.

Janke, K., 2014. Air pollution, avoidance behaviour and children's respiratory health: Evidence from England. Journal of Health Economics 38, 23-42.

Lambert, D., 1992. Zero-inflated Poisson regression, with an application to defects in manufacturing. Technometrics 34, 1-14.

MacKerron, G., Mourato, S., 2009. Life satisfaction and air quality in London. Ecological Economics 68, 1441-1453.

Moretti, E., Neidell, M., 2011. Pollution, Health, and Avoidance Behavior: Evidence from the Ports of Los Angeles. Journal of Human Resources 46, 154-175.

Mu, Q., Zhang, J., 2014. Air pollution and defensive expenditures: Evidence from particulatefiltering facemasks. (Available at http://dx.doi.org/10.2139/ssrn.2518032)

Neidell, M., 2004. Air pollution, health, and socio-economic status: the effect of outdoor air quality on childhood asthma. Journal of Health Economics 23, 1209-1236.

Neidell, M., 2009. Information, Avoidance Behavior, and Health: The Effect of Ozone on Asthma Hospitalizations. Journal of Human Resources 44, 450-478.

Piketty, T., 2014. Capital in the twenty-first century. Harvard University Press.

Pope III, C.A., Burnett, R.T., Turner, M.C., Cohen, A., Krewski, D., Jerrett, M., Gapstur, S.M., Thun, M.J., 2011. Lung cancer and cardiovascular disease mortality associated with ambient air pollution and cigarette smoke: shape of the exposure-response relationships. Environmental Health Perspectives 119, 1616. 
Sheu, M.L., Hu, T.W., Keeler, T.E., Ong, M., Sung, H.Y., 2004. The effect of a major cigarette price change on smoking behavior in California: a zero - inflated negative binomial model. Health Economics 13, 781-791.

Sieg, H., Smith, V.K., Banzhaf, H.S., Walsh, R., 2004. Estimating the general equilibrium benefits of large changes in spatially delineated public goods. International Economic Review 45, 1047-1077.

Silva, J.S., Tenreyro, S., 2006. The log of gravity. The Review of Economics and statistics 88, 641-658.

Smith, V.K., Desvousges, W.H., Payne, J.W., 1995. Do risk information programs promote mitigating behavior? Journal of Risk and Uncertainty 10, 203-221.

Vuong, Q.H., 1989. Likelihood ratio tests for model selection and non-nested hypotheses. Econometrica: Journal of the Econometric Society, 307-333.

Xie, Y., Zhou, X., 2014. Income inequality in today's China. Proceedings of the National Academy of Sciences 111, 6928-6933.

Zheng, S., Cao, J., Kahn, M.E., Sun, C., 2014. Real estate valuation and cross-boundary air pollution externalities: evidence from Chinese cities. Journal of Real Estate Finance and Economics 48, 398-414.

Zheng, S., Kahn, M.E., 2008. Land and residential property markets in a booming economy: New evidence from Beijing. Journal of Urban Economics 63, 743-757.

Zheng, S., Kahn, M.E., 2013. Understanding China's urban pollution dynamics. Journal of Economic Literature, 731-772.

Zheng, S., Wang, R., Glaeser, E.L., Kahn, M.E., 2011. The greenness of China: household carbon dioxide emissions and urban development. Journal of Economic Geography 11(5), 761-792.

Zweig, J.S., Ham, J.C., Avol, E.L., 2014. Air pollution and academic performance: evidence from California schools. Working Paper, Department of Economics, University of Maryland. Md. 
Table 1. Variable Definitions and Summary Statistics

\begin{tabular}{|c|c|c|c|}
\hline \multirow[t]{2}{*}{ Variable } & \multirow[t]{2}{*}{ Definition } & \multicolumn{2}{|c|}{ Mean (Std. Dev.) } \\
\hline & & Daily & Monthly \\
\hline PM2.5 & $\mathrm{PM}_{2.5}$ concentration $\left(\right.$ in $\mu \mathrm{g} / \mathrm{m}^{3}$ ) & $96.34(70.64)$ & $66.22(33.01)$ \\
\hline Mask & Taobao.com sales index of "mask" & $51.50(223.8)$ & $216.4(869.3)$ \\
\hline Filter & Taobao.com sales index of "air filter" & $6.285(20.66)$ & $35.30(85.82)$ \\
\hline Sock & Taobao.com sales index of "sock" & $77.71(160.3)$ & $621.0(967.8)$ \\
\hline Towel & Taobao.com sales index of "towel" & $24.66(52.09)$ & $212.3(300.2)$ \\
\hline \multicolumn{4}{|c|}{ Six Government Pollution Alerts: } \\
\hline Excellent & $1=$ "excellent" level, $0=$ otherwise & $0.068(0.252)$ & - \\
\hline Good & $1=$ "good" level, $0=$ otherwise & $0.366(0.482)$ & - \\
\hline lightly polluted & $1=$ "lightly polluted" level, $0=$ otherwise & $0.273(0.445)$ & - \\
\hline moderately polluted & $\begin{array}{l}1=\text { "moderately polluted" level, } \\
0=\text { otherwise }\end{array}$ & $0.139(0.346)$ & - \\
\hline heavily polluted & $1=$ "heavily polluted" level, $0=$ otherwise & $0.114(0.318)$ & - \\
\hline severely polluted & $1=$ "severely polluted" level, $0=$ otherwise & $0.040(0.196)$ & - \\
\hline \multicolumn{4}{|l|}{ Income Categories: } \\
\hline low income & $1=$ low-income group, $0=$ otherwise & - & $0.333(0.472)$ \\
\hline middle income & $1=$ middle-income group, $0=$ otherwise & - & $0.333(0.472)$ \\
\hline high income & $1=$ high-income group, $0=$ otherwise & - & $0.333(0.472)$ \\
\hline
\end{tabular}


Table 2. Daily Internet Sales of Self-protection Products as a Function of Air Pollution

\begin{tabular}{c|cc|cc|cc}
\hline & \multicolumn{2}{|c|}{$\begin{array}{c}\text { Standard negative } \\
\text { binomial model }\end{array}$} & $\begin{array}{c}\text { Zero-inflated negative } \\
\text { binomial model (ZINB) }\end{array}$ & $\begin{array}{c}\text { Zero-inflated Poisson } \\
\text { model (ZIP) }\end{array}$ \\
\hline & $(1)$ & $(2)$ & $(3)$ & $(4)$ & $(5)$ & $(6)$ \\
\hline Dependent variable: & mask & filter & mask & filter & mask & filter \\
\hline Government alert dummies: & & & & & & \\
blue sky (default) & & & & & & \\
lightly polluted & 0.0629 & $0.115^{* *}$ & $0.0906^{* *}$ & $0.136^{* * *}$ & -0.0471 & 0.0133 \\
moderately polluted & $(0.0592)$ & $(0.0499)$ & $(0.0480)$ & $(0.0387)$ & $(0.103)$ & $(0.0849)$ \\
& $0.224^{* * * *}$ & $0.236^{* * *}$ & $0.256^{* * *}$ & $0.271^{* * * *}$ & $0.252^{* * *}$ & $0.235^{* * *}$ \\
heavily polluted & $(0.0674)$ & $(0.0737)$ & $(0.0588)$ & $(0.0521)$ & $(0.0669)$ & $(0.0479)$ \\
severely polluted & $0.486^{* * *}$ & $0.405^{* * *}$ & $0.568^{* * *}$ & $0.457^{* * *}$ & $0.673^{* * *}$ & $0.459^{* * *}$ \\
& $(0.121)$ & $(0.0915)$ & $(0.102)$ & $(0.0861)$ & $(0.163)$ & $(0.124)$ \\
ln(PM2.5) & $1.176^{* * *}$ & $0.936^{* * *}$ & $1.316^{* * *}$ & $1.057^{* * *}$ & $1.462^{* * *}$ & $1.245^{* * *}$ \\
& $(0.179)$ & $(0.216)$ & $(0.169)$ & $(0.185)$ & $(0.323)$ & $(0.164)$ \\
Weather attributes & $0.306^{* * * *}$ & $0.0972^{* *}$ & $0.248^{* * *}$ & 0.0126 & 0.290 & 0.0445 \\
Other control variables & $(0.0470)$ & $(0.0473)$ & $(0.0443)$ & $(0.0444)$ & $(0.177)$ & $(0.117)$ \\
Vuong test & Yes & Yes & Yes & Yes & Yes & Yes \\
Observations & Yes & Yes & Yes & Yes & Yes & Yes \\
\hline
\end{tabular}

Notes: The regression estimates are reported based on equation (1). In the zero-inflated count models (columns (3)(6)), city dummies are used to model the probability that the dependent variable equals zero. Robust standard errors are reported in parentheses. Standard errors are clustered by city. Other control variables include; a constant, shopping festival dummies, national holiday dummies, city-fixed effects and a linear time trend. ${ }^{*} p<0.10 .{ }^{* *} p<0.05$. ${ }^{* * * *} p<0.01$. 
Table 3. Internet Sales as a Function of Air Pollution and Household Income

\begin{tabular}{l|cc|cc|cc}
\hline & \multicolumn{2}{|c|}{$\begin{array}{c}\text { Zero-inflated Poisson } \\
\text { model (ZIP) }\end{array}$} & \multicolumn{4}{|c}{ OLS } \\
\hline & $(1)$ & $(2)$ & $(3)$ & $(4)$ & $(5)$ & $(6)$ \\
\hline Dependent variable: & mask & filter & $\ln ($ mask+1) & $\ln$ (filter+1) & $\ln ($ mask) & $\ln ($ filter) \\
\hline $\ln ($ PM2.5) & $0.581^{* *}$ & 0.0275 & $0.808^{* * *}$ & -0.0556 & $0.926^{* * *}$ & 0.00429 \\
& $(0.279)$ & $(0.0956)$ & $(0.165)$ & $(0.111)$ & $(0.176)$ & $(0.123)$ \\
$\ln ($ PM2.5)*middle income & 0.0383 & $0.121^{* * *}$ & 0.00119 & $0.232^{* * *}$ & $-0.117^{*}$ & $0.151^{*}$ \\
& $(0.0268)$ & $(0.0344)$ & $(0.0617)$ & $(0.0786)$ & $(0.0631)$ & $(0.0818)$ \\
$\ln ($ PM2.5)*high income & $0.216^{* * *}$ & $0.103^{* *}$ & 0.124 & $0.275^{* * *}$ & 0.0464 & $0.156^{* *}$ \\
& $(0.0478)$ & $(0.0446)$ & $(0.0936)$ & $(0.0747)$ & $(0.102)$ & $(0.0583)$ \\
Income category dummies & Yes & Yes & Yes & Yes & Yes & Yes \\
Weather attributes & Yes & Yes & Yes & Yes & Yes & Yes \\
Other control variables & Yes & Yes & Yes & Yes & Yes & Yes \\
\hline Vuong test & $2.76^{* * *}$ & $2.98^{* * *}$ & & & & \\
Observations & 1326 & 1326 & 1326 & 1326 & 1264 & 1149 \\
R-squared & & & 0.843 & 0.888 & 0.820 & 0.882 \\
\hline
\end{tabular}

Notes: The regression estimates are reported based on equation (2). In the zero-inflated count models (columns (1)-

(2)), city dummies are used to model the probability that the dependent variable equals zero. Robust standard errors are reported in parentheses. Standard errors are clustered by city. Other control variables include; a constant, cityfixed effects and a linear time trend. ${ }^{*} p<0.10 .{ }^{* *} p<0.05 .{ }^{* * * *} p<0.01$. 
Table 4. A Placebo Test for the Self Protection Hypothesis

\begin{tabular}{|c|c|c|c|c|c|c|}
\hline & \multicolumn{4}{|c|}{ Zero-inflated Poisson model (ZIP) } & \multicolumn{2}{|c|}{ OLS } \\
\hline & Daily & Daily & Monthly & Monthly & Monthly & Monthly \\
\hline & $(1)$ & $(2)$ & (3) & (4) & $(5)$ & $(6)$ \\
\hline Dependent variable: & sock & towel & sock & towel & $\ln ($ sock +1$)$ & $\ln ($ towel+1) \\
\hline $\begin{array}{c}\text { Government alert dummies } \\
\text { blue sky (default) }\end{array}$ & & & & & & \\
\hline lightly polluted & $\begin{array}{c}0.0249 \\
(0.0299)\end{array}$ & $\begin{array}{l}-0.0158 \\
(0.0317)\end{array}$ & & & & \\
\hline moderately polluted & $\begin{array}{r}-0.00393 \\
(0.0301)\end{array}$ & $\begin{array}{c}0.0000259 \\
(0.0408)\end{array}$ & & & & \\
\hline heavily polluted & $\begin{array}{l}-0.0327 \\
(0.0363)\end{array}$ & $\begin{array}{c}0.0318 \\
(0.0517)\end{array}$ & & & & \\
\hline severely polluted & $\begin{array}{l}-0.00327 \\
(0.0667)\end{array}$ & $\begin{array}{c}0.0693 \\
(0.0623)\end{array}$ & & & & \\
\hline $\ln (\mathrm{PM} 2.5)$ & $\begin{array}{l}-0.0184 \\
(0.0348)\end{array}$ & $\begin{array}{l}-0.0746^{* *} \\
(0.0309)\end{array}$ & $\begin{array}{c}0.201 \\
(0.167)\end{array}$ & $\begin{array}{l}-0.137^{* *} \\
(0.0615)\end{array}$ & $\begin{array}{l}0.455^{* * *} \\
(0.0929)\end{array}$ & $\begin{array}{c}-0.107 \\
(0.0690)\end{array}$ \\
\hline $\ln (\mathrm{PM} 2.5) *$ middle income & & & $\begin{array}{l}0.0406^{* *} \\
(0.0192)\end{array}$ & $\begin{array}{c}0.0316 \\
(0.0388)\end{array}$ & $\begin{array}{l}0.00295 \\
(0.0417)\end{array}$ & $\begin{array}{c}0.0225 \\
(0.0478)\end{array}$ \\
\hline $\ln (\mathrm{PM} 2.5) *$ high income & & & $\begin{array}{c}0.0591 \\
(0.0495)\end{array}$ & $\begin{array}{c}0.103 \\
(0.0723)\end{array}$ & $\begin{array}{c}0.0169 \\
(0.0638)\end{array}$ & $\begin{array}{c}0.0940 \\
(0.0854)\end{array}$ \\
\hline Weather attributes & Yes & Yes & Yes & Yes & Yes & Yes \\
\hline Other control variables & Yes & Yes & Yes & Yes & Yes & Yes \\
\hline Vuong test & $8.05^{* * *}$ & $10.62^{* * *}$ & 0.89 & $2.29^{* *}$ & & \\
\hline Observations & 3085 & 3085 & 1326 & 1326 & 1326 & 1326 \\
\hline R-squared & & & & & 0.857 & 0.913 \\
\hline
\end{tabular}

Notes: Four zero-inflated regression estimates and two OLS estimates are reported. Robust standard errors are reported in parentheses. In the zero-inflated count models (columns (1-4)), city dummies are used to model the probability that the dependent variable equals zero. Standard errors are clustered by city. Other control variables are same as the related columns in Table 2 and Table $3 .{ }^{*} p<0.10 .{ }^{* *} p<0.05 .{ }^{* * *} p<0.01$. 